\title{
LETRAS \& IMAGENS: SIGNOS EM ROTAÇÃO
}

\author{
Annabela Rita*
}

Universidade de Lisboa, Portugal

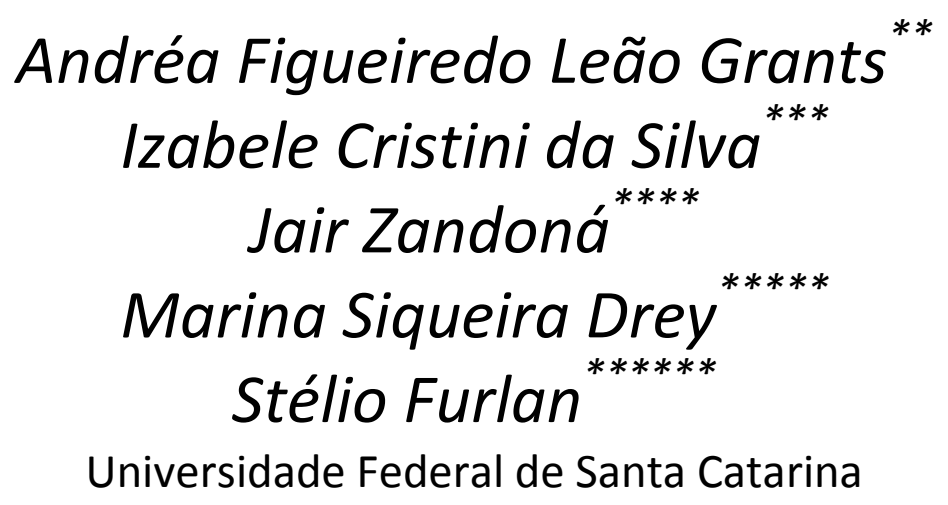

A revista Anuário de Literatura reúne, neste número, um conjunto de artigos que gravitam em torno das "Letras \& Imagens: signos em rotação". Através da história da cultura, as artes desenham um itinerário de pontos luminosos: obras em que os saberes dialogam, à distância das disciplinas, das práticas, dos autores, no espaço e no tempo. O desafio, aqui, será perscrutar alguns desses diálogos no desenho das imagens, na modulação do verbo, na escuta da música, na composição das cenas.

Essa seção temática se abre com o artigo de Camila Paula Camilotti, "Otelo" de Shakespeare além das fronteiras da página: uma análise de duas produções fílmicas, intituladas Othello e dirigidas por Orson Welles, em 1952, e por Oliver Parker, em 1995. O

Esta obra está licenciada sob uma Creative Commons - Atribuição 4.0

\footnotetext{
* Doutorada e Agregada em Literatura, é professora da Faculdade de Letras da Universidade de Lisboa e coordena o Grupo de Investigação 4 - Literatura e Cultura em InterArtes, do CLEPUL (Centro de Literaturas e Culturas Lusófonas e Europeias).

** Doutoranda e Mestre em Literatura pela UFSC. Bibliotecária do Sistema de Bibliotecas da UFSC. Coordenou o Portal de Periódicos UFSC (2009/jun.2014). Integra a Comissão Editorial da Anuário de Literatura.

**** Mestranda do Programa de Pós-Graduação em Literatura da UFSC e integra a Comissão Editorial da Anuário de Literatura.

${ }_{* * * * *}^{*}$ Doutor em Literatura pela UFSC, integra a Comissão Editorial da Anuário de Literatura.

***** Mestranda do Programa de Pós-Graduação em Literatura da UFSC e integra a Comissão Editorial da Anuário de Literatura.

${ }_{* * * * * *}$ Doutor e Mestre pela Universidade Federal de Santa Catarina. Atualmente é Professor Associado junto ao DLLV/UFSC. Atual Editor da Revista da ANPOLL e Editor da revista Anuário de Literatura.
} 
interesse principal do estudo dessas produções é observar à luz dos princípios de adaptação teatral de Jay Halio (2000), Patrice Pavis (1992) e Allan Dessen (2002).

Em O Olhar Recortado: considerações sobre o ponto de vista na adaptação cinematográfica de "Eu receberia as piores notícias dos seus lindos lábios", filme dirigido por Beto Brant e Renato Ciasca, baseado no romance do mesmo título de Marçal Aquino, Ricardo Magalhães Bulhões e Marcelo Magalhães Bulhões ajustam o foco do interesse na "visão tensa de um narrador-personagem que conta sua própria história", para concluir que a questão do ponto de vista é uma categoria reveladora das especificidades da literatura e do cinema.

Também na perspectiva dos estudos interartes, em A literatura e o livro didático: uma análise das relações intermidiáticas, Bonfim Queiroz Lima e Márcio Araújo de Melo analisam as relações que se estabelecem entre literatura e as outras linguagens artísticas no âmbito do ensino escolar a partir de pressupostos teóricos pautados nos estudos sobre a intermidialidade.

À sua vez, em Jonas Mekas - cinema em lampejos, Bruna Machado Ferreira apresenta reflexões acerca da criação cinematográfica de Mekas, considerado um dos realizadores e pensadores do cinema de vanguarda norte-americano, cuja compreensão do tempo e sua passagem implicam no abandono da cronologia e de qualquer linearidade narrativa.

Em seguida, no artigo Tradução coletiva e ilustração: estética da criação cinematográfica em Jane Austen, a partir de recortes metonímicos dos romances Razão e sentimento (1811), Orgulho e preconceito (1813), Emma (1815) e Persuasão (1817), Lemuel da Cruz Gandara e Augusto Rodrigues Silva Junior propõem um estudo comparativo entre os textos literários, as ilustrações e as imagens fílmicas, com base na estética da criação literária de Mikhail Bakhtin e nos conceitos de cinema literário, tradução coletiva e estética da criação cinematográfica.

Já em Van Gogh e o campo de trigo com corvos: da tela ao videoclipe, Maria Adélia Menegazzo e Isabella Banducci Amizo recorrem aos conceitos de multimídia e mixmídia, de Claus Clüver, e descrição e translação pictural, de Liliane Louvel, para pensar a questão da relação interartes no poema "À luz dos vegetais", de Contador Borges, no filme "Sonhos", de Akira Kurosawa) e no videoclipe "Corvos sobre o campo", da banda Tantra.

Na sequência, o artigo intitulado Merleau-Ponty, Lacan e Pessoa: o esfacelamento pulsional da visão, de Maicon Reus Engler, observa como o poema Ode Triunfal do 
heterônimo pessoano Álvaro de Campos pode expressar, a seu modo, várias ideias e posições que a filosofia alcança de forma teórica.

Marta de Almeida Loução Soares, em Parto da Viola para "Orpheu": Amadeo de Souza-Cardoso, o sensacionismo e os "hors-textes" de "Orpheu 3", após a contextualização artística e interdisciplinar da revista Orpheu, apresenta o resultado de uma investigação no espólio de Amadeo de Souza-Cardoso com o fito de refletir sobre o seu lugar na história da revista modernista lançada em Portugal, em 1915.

Por sua vez, Enrique Nuesch, no artigo El fantasma de las grietas: una especulación a-histórica, recorre ao conceito "forma del tiempo", de Siegfried Kracauer y George Kubler, e certas leituras de Agamben, Derrida y Deleuze, para ensaiar uma leitura da recepção da imagem mutilada do corpo humano na arte considerando discursos de historiadores, artistas e críticos ao longo da história.

A seção temática se encerra com o artigo de Claudio Alexandre Barros Teixeira, intitulado Wenceslau de Moraes, intérprete da cultura japonesa, sobre a recepção crítica e criativa da poesia nipônica na obra do escritor, diplomata e militar português Wenceslau Moraes, considerado o primeiro tradutor do haicai japonês para a língua portuguesa.

À guisa de remate, neste número também são publicados dois artigos com temática livre e uma entrevista. Em Subalternidade, representação e mercado: o que escrevem as moçambicanas? Anselmo Peres Alós reflete sobre a constituição da nacionalidade através das experiências de personagens de Lília Momplé e Paulina Chiziane, sem descurar de uma reflexão sobre a circulação de livros e a lógica do mercado editorial em tempos marcados pelos resíduos das políticas culturais colonialistas.

E Melina Pereira Savi, no artigo Como se Materializam as Fronteiras? A corporalidade da fronteira em "Borderlands/La Frontera", de Gloria Anzaldúa, conforme anunciado no título, relaciona a criação da "consciência da nova mestiza a partir da zona de fronteira" relacionando-a com a teoria do ciborgue, de Donna Harraway, e a teoria de uma ontologia de agenciamento realista, de Karen Barad.

Finalmente, em $\mathbf{O}$ fio das relações humanas: entre rasgos e remendos, Patricia Peterle e Elena Santi entrevistam o poeta e professor universitário Enrico Testa, que comenta sobre sua relação com a literatura e sua escrita poética.

Para concluir, gostaríamos de dedicar esta publicação, in memorian, à Profa. Dra. Zahidé Lupinatti Muzart, professora do Departamento de Língua e Literatura Vernáculas e uma das fundadoras do Programa de Pós-Graduação em Literatura da Universidade Federal 
de Santa Catarina. Pioneira nos estudos sobre mulher e literatura no Brasil, foi a fundadora do GT "A mulher na Literatura" da ANPOLL e realizou importantes pesquisas sobre essa temática.

Resta agradecer vivamente a todas as pessoas que contribuíram para a gestação deste número da revista Anuário de Literatura, que sai em parceria com Grupo de Investigação Literatura e Cultura em InterArtes, vinculado ao CLEPUL (Centro de Investigação da Faculdade de Letras da Universidade de Lisboa, em especial, à Fundação Calouste Gulbenkian, pela liberação do uso da imagem do pintor português modernista Amadeo de Souza Cardoso, cuja colagem de letras e imagens calha à perfeição para ilustrar o mote dos "signos em rotação" que anima a proposta do presente número.

Vale a pena lembrar que, se o diálogo das Artes e das Letras é instância de encontro de saberes e de inovação, este número oferece, sob a batuta de diferentes maestros, um autêntico concerto das Artes e das Letras num ano especial: 2015, um ano em que, no Brasil e em Portugal, se revisitaram os movimentos modernistas em congressos de modelo inédito, associando ao tradicional encontro científico uma rede de iniciativas multímodas (colóquios, seminários, exposições pictóricas e bibliográficas, lançamentos, debates, bailados, encenações, etc.) que os redimensionaram e os tornaram numa festa! E a festa continuará, agora, conosco a tomarmos a palavra para the dar novo impulso!

Com os melhores cumprimentos,

a Comissão Editorial.

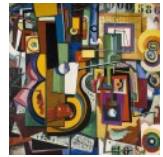

